\title{
PSICOLOGIA
}

\section{GERAÇÃO DE PÍLULAS AZUIS: A INTENSA BUSCA PELA FELICIDADE NA CONTEMPORANEIDADE}

\author{
DOI: http://dx.doi.org/10.31072/rcf.v9i1.562 \\ GENERATION OF BLUE PILLS: INTENSE LOOKING FOR HAPPINESS IN \\ CONTEMPORANITY
}

Victor Hugo Coelho Rocha1; Gabriele Pacheco Santos².

\begin{abstract}
RESUMO: A sociedade contemporânea carrega consigo uma gama de características que precisam ser alcançadas para que o indivíduo consiga a famigerada felicidade: comprar determinados produtos, pertencer a um determinado grupo, possuir determinadas formas de entretenimentos, etc. Contudo, todos esses empecilhos surgem para garantir a felicidade do sujeito, tornando os momentos melancólicos e tristes - que são naturais do ser humano inadmissíveis. Objetivou-se abordar nesta revisão de literatura como ocorre o processo de "sequestro" da subjetividade do sujeito, o qual reprimido em seus mais íngremes desejos, somatiza e adoece, abordando também o quão exacerbado tornou-se o uso descontrolado de medicamentos, além do mais, visa fazer uma reflexão acerca disto: por que torna-se mais fácil velar um problema a refletir sobre o mesmo? Fazendo um comparativo com os filmes de Matrix: por que é mais fácil tomar a pílula azul e ter uma vida velada a tomar a pílula vermelha e enxergar a verdade? Tratou-se de uma pesquisa bibliográfica realizada em periódicos científicos no período de abril a agosto de 2017. Através deste estudo, pode-se apontar que todo indivíduo carrega em si o desejo de alcançar a plena felicidade. Entretanto, sabe-se que a civilização e a cultura são dois dos grandes impasses que dificultam o alcance da utópica felicidade. A crítica que aqui é feita não é de banir os medicamentos até porque estes são de um imenso auxílio à prática psicoterápica -, tampouco à indústria farmacêutica, mas sim direcionado a ausência de reflexão.
\end{abstract}

Palavras-chave: Contemporaneidade. Felicidade. Psicanálise. Medicamentos. Depressão.

\begin{abstract}
Contemporary society carries with it a range of characteristics that need to be attained in order for the individual to achieve the famous happiness: to buy certain products, to belong to a certain group, to possess certain forms of entertainments, etc. However, all these obstacles arise to guarantee the happiness of the subject, making the melancholy and sad moments - which are natural of the human being - inadmissible. In this review of the literature, the objective of this study was to analyze the "kidnapping" of the subjectivity of the subject, which is repressed in its steepest desires, somatizes and falls ill, also addressing the exacerbation of the uncontrolled use of drugs, moreover, it aims to reflect on this: why is it easier to veil a problem to reflect on it? Doing a comparison with the Matrix movies: Why is it
\end{abstract}

\footnotetext{
1 Acadêmicos em Psicologia pela Faculdade de Educação e Meio Ambiente - FAEMA. Email: studiovictorocha@gmail.com. ORCID: https://orcid.org/0000-0002-4783-8359;

${ }^{2}$ Graduada em Psicologia e Orientadora desta pesquisa. Faculdade de Educação e Meio Ambiente - FAEMA. Email: gabrielepachecosantos@hotmail.com. ORCID: https://orcid.org/0000-0002-2645-7004.
} 
easier to take the blue pill and have a veiled life taking the red pill and seeing the truth? This was a bibliographic research carried out in scientific journals from April to August, 2017. Through this study, it can be pointed out that every individual carries the desire to achieve full happiness. However, it is known that civilization and culture are two of the great impasses that hinder the attainment of utopian happiness. The criticism that is made here is not to ban the medicines - even because they are of immense assistance to the psychotherapeutic practice - nor to the pharmaceutical industry, but rather directed to the absence of reflection.

Keywords: Contemporaneity. Happiness. Psychoanalysis. Medications. Depression.

\section{INTRODUÇÃO}

[...] Olha lá quem vem do lado oposto e vem sem gosto de viver

Olha lá os que os bravos são escravos sãos e salvos de sofrer Olha lá quem acha que perder é ser menor na vida

Olha lá quem sempre quer vitória e perde a glória de chorar

Eu que já não quero mais ser um vencedor, levo a vida devagar pra não faltar amor.

(...) Eu que já não sou assim muito de ganhar junto às mãos ao meu redor

Faço o melhor que sou capaz só pra viver em paz [...]

(O Vencedor - Los Hermanos). ${ }^{(1)}$

A música, de um modo geral, possui características reflexivas positivas, permitindo que, quem a ouça, identifiquese e reflita sobre a mesma. Este é o caso de "O Vencedor", da banda Los Hermanos. A música que inicia-se tal revisão foi proposta com o objetivo de demonstrar e explanar nesse trabalho o sentido de ser feliz, demostrando que a felicidade não é sempre ganhar, mas também perder e não fazer dessa perda uma vivência definitiva da vida. $\mathrm{Na}$ composição de Marcelo Camelo, torna-se notável que perder não é "ser menor na vida", e que a felicidade não está em ganhar todos os dias, e sim fazer o melhor para possuir uma vida plena.

Parte da explicação teórica para isto encontra-se no livro "A Psicoterapia ao Alcance de Todos", livro no qual Viktor Frankl (2) questionou o leitor sobre a noção básica acerca do desejo que o ser humano possui em ser feliz, questionando o leitor se não é verdade que o homem aspira, naturalmente, a ser feliz. E, finalizando os questionamentos, disse pensar que 0 homem não quer, necessariamente, ser feliz, mas sim quer um motivo para ser feliz, as razões que levam à felicidade.

Esta visão nunca foi tão atual: percebe-se, na sociedade contemporânea, o que Frankl chamaria de busca pela felicidade, na qual nota-se um gradiente de indivíduos que almejam a vida perfeita, e sonham, baseando-se nos ideais de felicidade já propagados pela sociedade: ter o carro do ano, o casamento dos sonhos, estudar na melhor universidade. Caso o sujeito não enquadre-se em um 
requisito, já é uma razão para ele conviver com a tão temida vida imperfeita.

Isto manifesta-se diretamente nas características psíquicas dos sujeitos contemporâneos: não sucumbir ou conseguir conviver com as metas sociais torna o ser humano cada vez mais melancólico. Simultaneamente, tal infelicidade não é aceita pela sociedade quase hedonista, que propaga o prazer a todo instante. Isto faz com que o ser humano busque, cada vez mais, formas de livrar-se destes sentimentos ditos como negativos.

O fato é que a generalização dos sentimentos faz com que muitos casos sejam vistos como depressão ou ansiedade, levando o sujeito a uma automedicação errônea, distanciando-o de um dos principais atos que deveria acontecer: a reflexão acerca da problemática moderna em não possuir momentos tristes.

Diversificadas são as formas que cada indivíduo desenvolve para se livrar da tão assustadora infelicidade - que vão desde gastar desenfreadamente como uma forma de camuflar a tristeza, até tentativas naturais como o tratamento fitoterápico ou a meditação -, uma destacou-se por ser extremamente utilizada:

OS medicamentos antidepressivos; as famigeradas "pílulas da alegria".

Mas afinal, vale a pena ignorar a verdade, com medo de encarar sua própria melancolia? Em uma sociedade que visa apenas esta felicidade, por que torna-se tão difícil não ser feliz a todo momento?

\section{MÉTODOS}

Esse trabalho foi realizado por meio de uma pesquisa bibliográfica que buscou nas bases de dados indexadas Scielo, BVS-Saúde, Pepsic, Redallyc, Google Acadêmico, artigos, trabalhos acadêmicos sobre a temática, livros teóricos. Utilizouse ainda uma referência musical e uma referência cinematográfica.

Os descritores utilizados foram: felicidade, contemporaneidade, psicanálise, medicamentos e depressão. Ao total foram encontradas vinte e oito literaturas e destas vinte e três foram selecionadas e incluídas para a construção deste trabalho, tais como artigos científicos, monografias, teses de doutorado, livros e periódicos eletrônicos, sendo uma referência em língua estrangeira (espanhol), incluindo os materiais que estivessem em consonância com o tema proposto. Como critério de exclusão foram selecionados aqueles trabalhos que não abordaram diretamente o objetivo proposto desta pesquisa. 


\section{FUNDAMENTAÇÃO TEÓRICA}

\subsection{Felicidade - de uma perspectiva histórica à contemporaneidade}

É um fato que todo e qualquer ser humano deseja a felicidade plena em sua mais completa forma: com uma vida perfeita, pessoas perfeitas, trabalho perfeito, estudo perfeito. Deste modo, não é difícil compreender que qualquer situação que migre para uma posição oposta à felicidade seja vista até mesmo como um caos pelo ser humano, levando-o a medidas paliativas para lidar com esses momentos sem a famigerada felicidade.

A busca pela felicidade no decorrer da história levou os seres humanos a percorrer uma vida em busca de um grande e comum objetivo, sendo este, a felicidade. Em todas as épocas vividas a meta final a ser alcançada sempre foi o desejo de uma vida melhor. Aristóteles (384 a 322 a.C.) baseava sua crença justamente nisso, ele acreditava que 0 objetivo de todo homem era a felicidade e a mesma só seria alcançada por ele se este tivesse uma vida repleta de virtudes e características positivas que o levassem a merecer tal felicidade.

Epicuro (341 a 270 a.C.) acreditava e menciona em uma de suas cartas sobre o respectivo tema, a felicidade, que 0 indivíduo somente pode alcançar a uma existência feliz a partir do momento que este abrir mão de todos excessos, de tudo que pode levar a sofrimento, como por exemplo, os demasiados compromissos sociais e medos que tornam-se empecilho para a famigerada felicidade, que se consegue levar o indivíduo a uma existência feliz. Sêneca (2 a.C. a 65 a.C.) partia do princípio que para encontrar a felicidade o sujeito deve se recusar a seguir a multidão, isto é, tomar consciência e entender de fato quem ele é, somente assim, conseguirá encontrar a felicidade ${ }^{(3)}$.

Russel (apud Graziano)(3) fala a respeito da necessidade social do homem de fazer parte do meio social, desta forma, ser inserido na sociedade tendo como objetivo a busca não somente da sua própria felicidade, mas também da felicidade do outro, mediante isto, a visibilidade da conceituação de felicidade transcende a noção de dádiva divina $e$ passar a ser vista como algo valioso que deve ser conquistado perante a promoção da felicidade ao outro.

Ao abordar sobre a vida, Aristóteles (apud Andreoni e Gomes)(4), diz que existem três formas de vida, a primeira forma corresponde àquela que satisfaz a vida de gozo, sendo que os homens identificariam o bem com o prazer, e, consequentemente, com a felicidade. A segunda forma de vida seria nomeada de política, associando bem à honra. Já a 
terceira forma chama-se vida da especulação, caracterizada pelo acúmulo de dinheiro. Independente da vida, compreende-se a felicidade como a finalidade de todas as ações, fazendo com que o indivíduo baseie suas escolhas com intuito deste resultado final.

Analisando a história, observa-se que a felicidade baseia-se sobre dois tipos de premissas, no que se refere a premissas de natureza extrínseca nota-se que a característica que se destaca é que o sujeito passa a buscar a felicidade para muito além de si mesmo, acreditando que poderá encontrá-la na aquisição de um carro novo, uma casa nova, um aparelho eletrônico que esteja em alta no mercado e os demais tipos de conquistas de caráter externo. De outro lado, referindo-se a premissas de natureza intrínseca o sujeito busca em si mesmo a felicidade, este tem como fonte sua própria existência, acreditando que tal felicidade somente será encontrada se este trabalhar seu interior, a si, transcender a tudo que está externo a ele ${ }^{(3)}$.

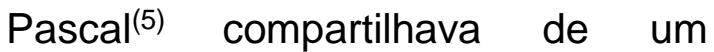
pensamento muito valioso e que se correlaciona com o que é decorrente dos dias de hoje, principalmente a aqueles indivíduos que apresentam ideação suicida. Usando tal exemplo, sabe-se que muitos são os julgamentos sobre estes, entretanto, de acordo com o pensamento de Pascal, até mesmo o sujeito que busca a morte, tendo por diversos métodos encontra-la, na verdade, tem como único objetivo ser feliz, a sua vontade de encontrar uma felicidade que já não existe no interior de si. Buscar a morte passa a ser uma forma desse sujeito de fugir da tão apavorante e sofrida infelicidade.

O mesmo acontece com um sujeito que pratica a automutilação, por exemplo. Brito $^{6}$ afirma que a automutilação não tem como intuito acabar com a vida, mas sim uma forma de transferir a dor psíquica para a dor física, havendo uma espécie de "êxito momentâneo", mesmo que seja um êxito negativo.

Deste modo, pode-se observar que até mesmo os atos mais dolorosos praticados pelo ser humano contra si mesmo têm como objetivo garantir uma espécie de alívio: mesmo que doloroso, este alívio possui uma característica de "retirar" da psique aquilo que fere e machuca - mesmo que para isso seja necessário gerar uma nova dor, a dor física.

Contudo, a felicidade almejada pelo ser humano é aquela que se realiza a partir de características quase perfeitas, as quais os ideais de felicidade perpetuamse, independentemente do local e época em que o sujeito se encontra. Tudo que 
foge deste ideal (como melancolia, tristeza, ou quando o indivíduo sente-se cabisbaixo e introspectivo) passa a ser visto com uma perspectiva patológica e negativa.

\subsection{Felicidade - a partir de uma perspectiva psicanalítica}

Fala-se que este ideal independe do tempo e lugar, pois, apesar de cada lugar possuir suas próprias características, possuem um ideal em comum: a felicidade plena. Qual a diferença dos pacientes na Viena de Freud e os sujeitos na contemporaneidade? São, em sua grande maioria, indivíduos que não vislumbram a felicidade (a pregada pela sociedade) em seu momento de vida atual. Assim como os pacientes de Freud somatizavam perdendo a sensibilidade de certas partes do corpo, atualmente também percebemos um gradiente de sujeitos que somatizam com dores físicas a partir de seu emocional. A compensação vem, em grande proporção, através do uso farmacológico, como uma maneira de camuflar e ignorar a dor que deveria ser levada para a psicoterapia. Os fármacos atuam como uma espécie de "pílulas da felicidade", embora o efeito seja de curta duração.

O uso farmacológico não é, primordialmente, negativo, pelo contrário: em muitos casos de psicoterapia, é importante que também seja feito um acompanhamento medicamentoso como forma de auxiliar o paciente. A crítica é relacionada, então, ao uso indevido, como usar o medicamento para esquecer ou ignorar os sentimentos, e não refletir sobre os mesmos.

A busca ao prazer visando a necessidade de alcançar a felicidade é vista como uma forte marca da nossa sociedade contemporânea. Tenta-se evitar todo e qualquer tipo de contato com o sofrimento. Entretanto, permitir uma busca desenfreada e um alcance da suposta evitação do sofrimento seria muito perigoso para a estrutura da personalidade do indivíduo, pois torna-se necessário a introdução do princípio de realidade. Segundo Saroldi ${ }^{(7)}$, há uma dificuldade na atualidade em pensar coletivamente e essa busca por prazer de forma exacerbada introduz o homem no mundo da barbárie, distanciando-o da cultura. Para a autora, a renúncia - que conduziria aos processos civilizatórios - é algo que tem sido expurgado do imaginário comum. Vargas Llosa(8) destaca que têm-se valorizado o prazer, a fuga ao tédio, a leveza. Contudo, a sociedade (e os seres que nela vivem) não vive um processo hedonista de prazer atemporal, onde tudo está sempre bem, e o ser humano sempre 
é regido e tem todas as suas decisões tomadas pelo Id.

O grande precursor da psicanálise, Sigmund Freud, ao falar sobre a primeira tópica do aparelho psíquico, fazendo referência a prazer e desprazer, chegou à conclusão que não existe a possibilidade de encontrar prazer sem também experimentar o desprazer, torna-se uma meta utópica, Freud dizia que quanto maior o nível de prazer no interior do aparelho psíquico humano maior também era o desprazer que este experimentava e que precisava ser descarregado por algum meio, pelo fato de vivermos em sociedade, uma das formas utilizadas é através de exercícios, de motricidade, e é justamente por esse motivo que se pauta tal impossibilidade de satisfação irrestrita, pois o fato de vivermos em sociedade nos priva em demasiadas formas de viver nossos mais íngremes desejos ${ }^{(9)}$.

Suzuki (apud Sebold) ${ }^{(10)}$ fala sobre o "distanciamento dos afetos", no qual o homem encontra-se distante da experiência de felicidade, alegria e sentimentos que o levam a tal estado feliz, por isto, em muitas situações este passa a viver em estados depressivos, que influencia na maneira como o indivíduo relaciona-se com o outro e em como vive no mundo e nos rumos que está dando aos destinos. Empiricamente, pode-se perceber as consequências desse processo, o enfraquecimento do laço social, amizade, família, além disto, o ser humano cultiva uma rotina demarcada por horários de durabilidade e prazos de validade, onde o tempo é o senhor do nosso destino, uma caminhada constante em direção a lugar nenhum. Além do mais, o ser humano encontra-se submetido a um ideal social que preexiste ao próprio nascimento, pois mesmo antes de nascer, aqueles que se dedicarão ao próprio nascimento e cuidado já predeterminam os destinos e tornam as escolhas limitadas, logo, cada indivíduo passa a ser construídos por ideais e expectativas que não é de si próprio, mas sim inicialmente de seus pais e mais tarde da sociedade de acordo com os critérios de certo e errado perante a civilização.

Defronte a dificuldade do alcance da felicidade plena, surge um estado de infelicidade considerada por Freud como de mais fácil alcance. Inada (9) acredita que existe fontes que proveem a infelicidade no interior do indivíduo, sendo os relacionamentos humanos podendo ser muitas vezes muito inconstante $e$ superficial, o próprio mundo exterior que refere-se também a sociedade com seus pré julgamentos e determinações e o próprio corpo, demarcado pela insatisfação do sujeito com si mesmo, buscando 
sempre a perfeição. Segundo Suzuki (apud Sebold) (10) o que se impregnou no interior do sujeito da contemporaneidade é que se tem muito mais valor socialmente ter algo, e apresentar algo, do que ser, e dentre ser, ser verdadeiramente feliz.

Inicialmente, o indivíduo é um ser meramente biológico que busca satisfação das necessidades ligadas somente à sobrevivência, mais tarde, conforme é inserido em seus interior os princípios sociais, tais como, o que é errado e o que é correto, o homem passa a se tornar cada vez mais insatisfeito com o que tem e com o que é, buscando cada vez mais por desejos e necessidades que excedem a verdadeira necessidade, desta forma, no impossível alcance de tais desejos, o ser humano passa a ser reprimido, tendo seus desejos postergados ou desviados de sua finalidade original ${ }^{(9)}$.

Desta forma, de acordo com o jargão social, para "ser alguém na vida" é preciso ter uma profissão, um bom emprego, casa própria, uma família, a possibilidade de consumir produtos de boa qualidade e recém-lançados pelo mercado, objetivos que acabam sendo elencados de forma inconscientemente levando o indivíduo acreditar que somente encontrará a felicidade se aderir ao sistema capitalista que aparece vinculada a possibilidade de consumo. Observa-se que foi dada a felicidade um caráter de dever, aparecendo atrelada também ao status social e a imagem e supervalorização do corpo ${ }^{(10)}$.

\subsection{Vida em simulacro}

Antigamente, sentimentos negativos não podiam ser mencionados e muito menos sentidos pela espécie humana, era proibido fazer menção de termos que fizesse conotação com sofrimento, vivenciar suas dores representava fraqueza. Contudo, Bruckner destaca que o que deve desaparecer do discurso do sujeito não é o fato de sentir dor e sofrer, mas sim 0 fato de expressar tais sofrimentos através de vias públicas, como a expressão através do discurso ou até mesmo das redes sociais, exigindo-se que a espécie humana passe a simular a própria felicidade Bruckner (apud Sebold) (10), desta forma o indivíduo passa a reproduzir papéis, vivendo em simulacro.

Ser plenamente feliz em uma sociedade que obriga, a todo o momento, mediar desejos tornou-se um objetivo inacessível. Logo, existir na contemporaneidade trata-se muito mais de contracenar papéis do que viver de fato quem se é, creditado isto a sociedade que determina o que é socialmente aceitável, sendo que tudo que transcender a isso se torna promíscuo e patológico. Deste modo, alcançar a felicidade é uma ilusão de 
caráter

social,

organizada

e desempenhada pela própria sociedade, como se refere Fontenelle ${ }^{(11)}$, pois a linha entre o aceitável e o profano é muito tênue.

Assim, o indivíduo encontra-se obrigado a todo o momento sublimar seus desejos por outros mais socialmente aceitos. Mas que o impede de alcançar a tão desejada meta da felicidade?

$\mathrm{Na}$ atual sociedade, percebe-se que foi retirado do indivíduo o direito de sofrer, de se permitir sentir-se tristonho, pois este, ao ser percebido assim, passa a ser rotulado como 0 desanimado, 0 depressivo, o "baixo-astral"; impera-se a necessidade de ser feliz, pois a mesma sociedade que o produz também o rejeita, rejeita a sua possibilidade de perceber-se fora da carga de expectativa lançada sobre ele por parte do sistema civilizatório e suas exigências. Hoje é preciso ser feliz, diante do fácil acesso a tudo, tecnologias e meios de comunicações não há espaço para o fraco, o controle social se intensifica cada vez mais garantindo que a sociedade se comporte e apresente um posicionamento aceitável, retira-se o luto e impera-se a felicidade. Mediante a isto, o indivíduo não se permite sofrer, vivenciar sua tristeza, o que este poderá necessitar apenas da oportunidade de vivenciar sua dor e não da sua retirada. Impera-se o gozo, pois a real necessidade é ter a sonhada felicidade e afastar tudo que provoca sofrimento (12).

Na sociedade contemporânea, notase que 0 ser humano precisa estar cotidianamente feliz, propagando uma falsa ideia de felicidade imediata. Bauman (apud Ferreira) ${ }^{(13)}$ compara a subjetividade com 0 fetichismo da mercadoria propagado pelo anseio por uma felicidade instantânea e perpétua, assim, quanto mais o indivíduo, convocado a responder como um personagem fictício da sua própria vida, perde o norte de suas produções subjetivas singulares, devido à perda da sua individualidade sobre seus comportamentos, mas a sociedade irá devolver-lhe uma subjetividade espetacularizada, no qual o mesmo padrão de comportamentos é identificado.

Isto é, à medida que o sujeito nota que, na sociedade, aqueles que estão cabisbaixos, tristes e cansados são rotulados como depressivos, ele irá procurar soluções imediatas, para que quando sinta-se de tal maneira, consiga ter em mãos algo que retire a dor e, quase que automaticamente, devolva-lhe o ideal de felicidade.

Por não permitir-se viver a genuidade do que sente, não permitir-se vivenciar momentos difíceis, este sujeito vive, então, através de um mecanismo egóico 
representado por uma sociedade também egóica.

O Ego não é algo que tem sua existência do nada, ele é construído no decorrer da existência do sujeito, assim como o ld e o Superego, o Ego também tem sua função, sendo esta a de mediar as pulsões do Id que grita pelo prazer e as exigências do superego que atua ao lado das exigências sociais, que realmente leva o indivíduo a realidade socialmente imposta. Desta forma, entende-se que é a personalidade que desenvolve os mecanismos de defesa necessário do Ego, tendo entre os principais mecanismos de defesa do Ego existentes se encontra 0 mecanismo de negação que consiste simplesmente na recusa do sujeito em consentir com situações que levam ao sofrimento, que causa angustia nesse sujeito ${ }^{(14)}$.

Ao negar sua dor, o homem recalca para si suas angústias não as externalizando, dificultando sua elaboração. Logo, o homem, sujeito o qual é diferenciado dos animais pela capacidade de comunicar-se pela palavra, guarda para si e sofre. Sabe-se que corpo e palavra são partes indissociáveis da existência, o corpo que se apresentará ao médico será o corpo de um ser falante, além do mais, o corpo também falará através de suas disfunções e dores. A ciência médica atua sobre o corpo humano de acordo com aquilo que pode ser visualizado externamente, é um saber universal, se não mecânico. Na medicina, a doença, desde os primórdios, é diagnosticada por seus sinais e sintomas, o sintoma é identificado e examinado até ser formado o quadro nosológico da doença. Entretanto, seria apenas a medicina a única suficientemente capaz de responder as respostas do corpo? Para encontrar tal resposta, pode-se voltar a antiga Viena, onde o Doutor Sigmund Freud era procurado para atender pessoas que apresentavam sintomas, tais como paralisação, que fugia totalmente as explicações cientificas da época. Freud encontrou-se com pacientes sobre os quais a ciência não tinha todo o saber, na qual a medicina não conseguia exercer o controle e não sabia o que desenvolver para promover a cura a sujeitos com tais sintomas, ainda existia algo que iria além da ideia de corpo anatomo-fisiológico, existiria uma causa subjetiva para tais somatizações, o anseio por uma felicidade que the eram retirados pela própria sociedade, onde o sujeito sofre e não pode externalizar sua dor. Percebe-se que as exigências em não externalizar o sentimento real do sujeito possui uma carga histórica, não é algo da contemporaneidade, na era Vitoriana já se 
percebia essa imposição sobre o homem ${ }^{(15)}$.

A perpetuação dessa impossibilidade lançada sobre o sujeito contemporâneo de ser e expressar o que realmente se é teria uma carga cultural transpassando décadas até os dias de hoje?

Considerando que este sujeito convive em sociedade e carrega uma carga que antecede sua existência, a resposta é sim. Afinal, esse sujeito não tem controle direto sobre as cobranças impostas pela sociedade.

\subsection{Felicidade e a psicofarmacologia -} implicações quanto a banalização do medicamento

Cada sujeito tem sua constituição pautada sobre uma perspectiva que é biológica, psicológica e social, o que chama-se de biopsicossocial, e compreender isto é compreender também certas determinações da sociedade. Margarido (16) afirma que a grande problemática envolvendo a psicofarmacologia quando trata-se de depressão, por exemplo, é a banalização: com o avanço farmacológico e o marketing que é realizado sobre os medicamentos, pessoas com depressão leve, que a priori não precisariam utilizar o medicamento, passam a fazer uso indevido. Isto porque, em primeira instância, os medicamentos devem ser utilizados apenas em casos de depressão severa.

Isto faz com que ocorra não apenas uma banalização, mas uma espécie de "solução rápida". A problemática não está em utilizar o medicamento - quando prescrito pelo médico psiquiatra, o medicamento pode ser de grande ajuda -, e sim em como a psicoterapia passa a ser ignorada nesses casos, além da dependência do paciente. Mesmo que seja necessário fazer uso do medicamento, é igualmente importante que o sujeito passe pelo processo psicoterápico, para que possa refletir sobre as questões que 0 deixam de tal maneira.

Considera-se isto, pois o problema da medicação é que o sujeito passa a ver a solução, o modo de livrar-se da dor, através da lógica psicofarmacológica Margarido ${ }^{(16)}$. Isto faz com que o indivíduo prive-se de outras possíveis ajudas, bem com a terapia, por ver que sua "cura" se restringe ao medicamento. $\mathrm{O}$ sujeito, então, perpassa por certa dependência, e quando sentir-se triste, provavelmente fará uso do medicamento com intuito de que o sofrimento passe.

Um sujeito que desenvolva sintomas tais como fadiga, dores corporais, diminuição de apetite, perda de peso, alterações de sono, facilmente pode ser diagnosticado pela medicina como um 
paciente que apresenta um quadro clínico de depressão. Entretanto, necessita-se atentar que um apunhado de sintomas não determinam um quadro patológico, diagnósticos pautados apenas em aspectos nosológicos correm um preocupante risco de não serem fidedignos com a realidade do indivíduo. A depressão torna-se cada dia mais naturalizada, Prata (17) indo além em pesquisas, descobriu que atualmente a depressão é um grande problema de sáude de caráter público, atinge milhões de pessoas em toda terra, independente de valores culturais, crenças e etnias, além do mais, de acordo com o aumento da incidência de depressão, esta apresenta grande probabilidade de se tornar a segunda maior doença mundial até 2020. E torna-se ainda mais assustador quando se analisa os dados das vendas de fármacos, sendo as "pílula da felicidade", infalíveis contra a depressão, as mais vendida atualmente no Brasil. A que deve esse aumento? Seria a negligência de muitos profissionais da saúde que padronizam sintomas e diagnosticam ou ao próprio sujeito que se automedicam e determinam o próprio diagnóstico?

Dada à globalização, o avanço da mídia que alcança cada dia mais um número maior de pessoas e ao fato de o enfrentamento de algum sofrimento ter se tornado "fora de moda", a indústria farmacêutica passou a contar com um enorme arsenal de medicamentos, as mágicas "pílulas da felicidades", as quais tem solução para tudo, para combater tudo que possa provocar algum tipo de angústia e mal-estar, desde a depressão até a uma dor de cabeça. Nota-se que não sente-se dor de cabeça porque está cansado e esta foi a forma que o emocional escolheu para se expressar, através do corpo; se existe tal dor é porque algo de errado está acontecendo no organismo, mediante isto, a internet torna-se 0 instrumento de identificar uma patologia sem a necessidade de ir ao médico. Logo, uma pessoa que está com alterações de sono e de apetite por trabalhar exaustivas horas e não conseguir realizar suas refeições no horário correto como de costume e, consequentemente, sente-se cansada, com dores corporais, com muitos sintomas que nem possuem ligação direta com a depressão, mas que geralmente dão ao indivíduo a ideia de sofrimento e mal estar que deve ser remediado com antidepressivos, se diagnostica com depressão, e isto tudo, sem sair de casa.

A partir dessas explanações, Prado e Gomes ${ }^{(4)}$ observam que torna-se ambígua a atuação na vida do ser humano, ainda que tenha como objetivo proteger 0 indivíduo de situações que o leve ao 
sofrimento, esta acaba por provoca-lo, o que acaba levando o individuo desenvolver sentimentos negativos contra a própria sociedade que está inserido.

Proteger-se desse sofrimento e interpretá-lo de maneira errônea torna o sujeito um eterno ser humano que busca a felicidade e meios de alcançá-la.

$\mathrm{Na}$ logoterapia, teoria de Viktor Frankl, o mesmo diz que quem busca a felicidade em si, parece desejá-la de modo absoluto, incondicional e individual, desconsiderando que nela esteja implicada uma concepção de "razão" para ser feliz ela não existe por existir, algo gera esta felicidade. A felicidade não deve ser buscada, se houver uma razão para esta, ela surgirá automaticamente. A máxima da logoterapia é "não se pode perseguir a felicidade", buscá-la. Se buscar, não é uma felicidade verdadeira, e sim um desejo ${ }^{(18)}$.

A felicidade não é uma totalidade hedonista, ela é natural, e devido tal naturalidade irá surgir quando esta por si só encontrar razão para existir. Compreender isto é compreender que não existem seres humanos felizes todos os dias, a todo momento, pois isto não seria uma verdade, e sim um desejo. Se não houverem momentos tristes, como o ser humano pode discernir tristeza de felicidade?
Apresentar algum comportamento que fere aquilo que é imposto pela sociedade apresenta-se de forma tão preocupante que o indivíduo abriu mão do direito de olhar para si, de analisar quem este é e porque sente-se de determinada forma. Nota-se a razão pelo descaso direcionado à psicoterapia, a qual é imprescindível para que o sujeito consiga olhar para si e identificar-se, perceber-se além de uma patologia. $O$ sujeito do século XXI tornou-se um ser que tem medo de pensar, pois pensar dói, e a dor não é compatível com a felicidade, e se não é compatível, esta também não merece ser tolerada. Criou-se uma aversão à possibilidade de ser confrontado consigo mesmo, com a realidade existente dentro de si, logo, negar a realidade tornou-se algo prazeroso, que pode ser alcançado com doses medicamentosas.

Isto é, o sofrer e o sentir-se triste, mesmo que momentâneos, tornam-se inadmissíveis perante a sociedade, e quanto mais o sujeito tenta proteger-se (a partir do uso exacerbado de medicamentos, por exemplo), mais ele irá sofrer, pois enquanto não ir à fundo, refletir, considerar e aceitar quais são os movimentos pessoais que causam essas dores, o sujeito só conseguirá camuflá-la, e não tratá-la. 
Mas afinal, vale a pena ignorar a verdade, com medo de encarar sua própria melancolia.

\subsection{Felicidade e Matrix - pílula azul ou pílula vermelha?}

No filme Matrix ${ }^{(19)}$, o telespectador é apresentado por uma concepção de ambiguidade entre encarar a verdade e conviver com uma camuflagem. Em uma cena dos filmes, Morpheus apresenta a Neo a ideia de levar uma vida comum ou encarar a verdade. Morpheus fala que Neo deveria fazer uma escolha importante: escolher entre a pílula azul e a pílula vermelha.

Apresentando que o ser humano é uma espécie de escravo da sociedade, Morpheus diz que não pode-se explicar o que é a Matrix (uma possibilidade elencada seria de que a Matrix seria uma metáfora para designar o próprio conceito de vida) naquele momento, mas que se Neo quisesse ver a verdade, poderia. Para isto, ele deveria fazer a escolha entre a pílula azul, que garantiria que ele acordasse em sua casa e levaria uma vida comum, ou a pílula vermelha que mostraria a verdade. Morpheus usa como analogia $o$ fato de que tomar a pílula vermelha deixaria Neo no País das Maravilhas, e Morpheus mostraria até onde iria a toca do coelho - uma referência à Alice no País das Maravilhas
-, para que Neo passasse a compreender o que a Matrix era, de fato, por mais difícil que fosse.

Tomar a pílula azul garantiria conforto, felicidade e estagnação em uma vida comum. Enquanto que a pílula vermelha gera um extremo desconforto, por mostrar a verdade: que o ser humano nem sempre terá apenas momentos confortáveis, e que para compreender o conforto, é necessário compreender características ditas como negativas.

A partir disso, é feito um questionamento ao leitor: a sociedade têm vivido em uma geração de pílulas azuis? Uma geração que prefere camuflar aquilo que é difícil, e considerar as falsas ilusões de felicidade a encarar a verdade?

A geração de pílulas azuis leva uma vida dita como normal pela sociedade: trabalhe, case, viva, viaje, e faça tudo isso com conforto e um sorriso no rosto. $E$ caso seja difícil sorrir, existe sempre uma pílula para ajudar.

\section{CONSIDERAÇÕES}

A partir da revisão de literatura utilizada, nota-se que, na sociedade contemporânea, grande parte dos sentimentos melancólicos são vistos como sinônimo de depressão. Isto faz com que a pessoa que se sinta com tais características busque resultados rápidos e que ela julgue eficazes para tirar a 
melancolia e tristeza de si. Cada vez mais, o mecanismo utilizado se encontra voltado para a indústria farmacológica.

$\mathrm{Na}$ sociedade contemporânea, são estabelecidas várias características que ditam o que o sujeito precisa ter ou fazer para ser feliz. Isto faz com que, cada vez mais, os sentimentos como tristeza sejam vistos apenas como negativos e inadmissíveis. A partir do momento em que o indivíduo enquadra-se em vários pontos sociais (como emprego, casamento, filhos, estudo), torna-se inaceitável que ele tenha momentos de desprazer.

Logo, nota-se que o sonho da sociedade é como uma utopia do hedonismo: onde tudo é prazeroso e indolor. O fato é que a realidade é manifestada através de pontos positivos e negativos. A partir disso, o necessário seria refletir a partir desses pontos, mas como torna-se inaceitável possuir pontos negativos, os indivíduos passam a buscar resultados rápidos para obter uma vida inteiramente prazerosa, ignorando qualquer característica que julguem como negativa.

E o que motiva essa busca? Justamente a predeterminação da sociedade sobre este indivíduo, o qual perde seu direito de sujeito pensante, tendo sua subjetividade e percepção de si roubada pelo sistema, e, por meio disto, percebe-se que não é algo único da contemporaneidade, mas sim uma realidade que acompanha o passar dos séculos, e que Foucault (20) retrata perfeitamente em suas análises da sociedade dos séculos passados com a atual condição e posicionamento da sociedade do século XXI, o autor retrata em seu livro Vigiar e Punir que entre os séculos XVII e XVIII a sociedade soberana utilizava o suplício e a punição corporal como forma de controle sobre a população. Em sua obra, A história da Loucura, Foucault(21) irá retratar que no Renascimento tudo que fosse identificado como "errante e perturbador da paz social" deveria ser extinto, e desta forma, assistiase mensalmente estranhos navios sendo lotados de "loucos", a nau dos loucos, navios os quais levavam sua carga insana de uma cidade para outra como forma de controle, pois tais loucos eram confinados e considerados a ociosidade da sociedade.

Tal necessidade de controle por parte da sociedade ainda é identificada no século vigente, mas o que mudou? Diferese que as cruéis punições corporais como forma de controle foram substituídas pela desapropriação da autenticidade do sujeito, do direito de ser ele mesmo, sujeito que sente, fala e manifesta. $\mathrm{Na}$ contemporaneidade, expressar o que 
sente tornou-se sinônimo da loucura, fator que perturba a ordem do sistema social, fator o qual percebe-se impregnado de tal forma que o próprio indivíduo abdica do seu direito de ser e sentir e assume uma condição passiva, encenando e adoecendo.

Aceitar-se em felicidade e infelicidade tornou-se difícil, e o ser humano costuma buscar formas para camuflar os momentos que não são prazerosos, desconsiderando-os como naturais. Logo, há uma busca rápida pela felicidade, e, infelizmente, é uma busca que não valoriza, em sua grande maioria, a reflexão da psicoterapia.

Através deste estudo, pode-se apontar que todo indivíduo carrega em si o desejo de alcançar a plena felicidade. Entretanto, sabe-se que a civilização e a cultura são dois dos grandes impasses que dificultam 0 alcance da utópica felicidade. Além disso, encontra-se 0 princípio de realidade que faz o princípio de prazer reduzir suas expectativas e converte-se a ele, o qual impõe uma série de limites ao projeto de vida feliz do indivíduo. Pôde-se observar também que ao mesmo tempo em que a civilização cria meios para proteger os indivíduos das fontes de sofrimento ela acaba por ser tornar ambígua a partir do momento que passa a produzir o próprio e temido sofrimento no interior do sujeito que é reprimido em sua liberdade de experimentar e sentir. Mediante isto, reforça a condição miserável do ser humano, ambiguidade que gera no seio da sociedade um sentimento de hostilidade e ao mesmo tempo obediência direcionado a civilização. Objetivou-se abordar nesta revisão de literatura como ocorre esse processo de "sequestro" da subjetividade do sujeito, o qual reprimido em seus mais íngremes desejos, somatiza e adoece, abordando também o quão exacerbado tornou-se 0 uso descontrolado de medicamentos.

A crítica que aqui é feita não é de banir os medicamentos - até porque estes são de um imenso auxílio à prática psicoterápica -, tampouco à indústria farmacêutica. Primeiramente, nota-se que, em vários casos, o uso medicamentoso não é acompanhado de uma prescrição médica, caso que não deve acontecer: o psiquiatra saberá ver o sujeito com um olhar individual, e a partir disso saberá se o paciente precisa do medicamento, e se precisar, qual é a melhor dosagem e o melhor medicamento, estimulando também a psicoterapia. Em segundo lugar, a crítica aqui feita é realizada acerca da ausência de reflexão: não é refletir se deve ou não tomar o medicamento, mas refletir sobre as razões e emoções que levam ao ato em 
questão. $E$, além disso, propor que a psicoterapia, em auxílio com a psiquiatria, mostra-se como uma prática eficaz, buscando sempre um interesse em comum: ajudar o indivíduo.

Os profissionais da psicologia devem visar sempre a reflexão do indivíduo, e fazer isto baseando-se na prática reflexiva. Aqui, antes mesmo de refletir acerca das possíveis soluções, é importante refletir sobre as causas: por que o sujeito contemporâneo não consegue ter momentos de dor ou tristeza? Por que torna-se tão difícil refletir sobre o que está causando aquilo? Muitos indivíduos não permitem-se fazer isso, recorrendo rapidamente a formas de amenizar a dor.

Por que a atual geração tornou-se uma "geração de pílulas azuis"? Que preferem tomar a pílula azul - aqui, a pílula azul não é, necessariamente, um representativo medicamentoso, mas toda $\mathrm{e}$ qualquer forma que o sujeito encontra para ignorar o problema - e fingir ter uma vida perfeita, a tomar a pílula vermelha, que pode ser dolorosa e verdadeira, mas que é o único caminho para a real felicidade?

A felicidade não é uma vida sem momentos tristes, pelo contrário: a felicidade é nem sempre estar feliz e alegre, mas refletir acerca desses momentos, os causadores, e então conseguir lidar e rumar naturalmente até ela. A felicidade não é buscada, ela o busca.

Conclui-se que 0 trabalho não termina aqui: é um tema que sempre deve ser refletido, e, ainda hoje, é pouco falado e muitas vezes até mesmo ignorado, mas começar a abordá-lo é uma forma de começar a diminuir o estigma social que tem-se sobre o tema, pois consiste em ver além do estigma, do estereótipo e da utopia de que a felicidade é uma constância e de que estar introspectivo é sempre ruim.

\section{REFERÊNCIAS}

1. Camelo M. Los Hermanos, Ventura: O Vencedor [CD-ROM]. Rio de Janeiro (RJ): BMG Brasil, 2003.

2. Frankl V. La Psicoterapia Al Alcance de Todos. 7aㅡ ed. Espanha: Herder; 2009.

3. Graziano LD. A Felicidade Revisitada: Um Estudo Sobre Bem-Estar Subjetivo na Visão da Psicologia Positiva. [Tese de Dourado]. São Paulo (SP): Universidade de São Paulo - USP; 2005. [citado em 20 de agosto de 2017]. Disponível em: http://www.teses.usp.br/teses/disponiveis/4 7/47131/tde-23052006-164724/en.php.

4. Gomes VMLR, Andreoni R, Gomes LB. As Emoções e a Felicidade na Contemporaneidade: Reflexões em Torno Da Abordagem Discursiva da Animação Divertida Mente. Rev Conexão Comunicação e Cultura 2016; 15(30): 241 255. [citado em 20 de agosto de 2017]. 
Disponível:

http://www.ucs.br/etc/revistas/index.php/co nexao/article/view/4626/2850.

5. Sponville AC. A Felicidade, Desesperadamente. 4a ed. São Paulo (SP): Martins Fontes; 2010. [citado em 20 de agosto de 2017]. Disponível em: http://abdet.com.br/site/wp-

content/uploads/2014/10/A-Felicidade-

Desesperadamente.pdf.

6. Brito I. Ansiedade e Depressão na Adolescência. Rev Portuguesa de Medicina Geral e Familiar 2011; (27)2: 208-214. [citado em 20 de agosto de 2017]. Disponível em: http://rpmgf.pt/ojs/index.php/rpmgf/article/vi ew/10842/10578.

\section{Saroldi N.O Mal-Estar na} Civilização: As Obrigações do Desejo na era da Globalização. 1aㅡ ed. Rio de Janeiro (RJ): Civilização Brasileira; 2012.

8. Llosa MV. A Civilização do Espetáculo: Uma Radiografia do Nosso Tempo e da Nossa Cultura. Rio de Janeiro: Objetiva; 2013.

9. Inada JF. Felicidade e Mal-estar na Civilização. Rev Digital AdVerbum 2011; 6(1): 74-88. [citado em 20 de agosto de 2017]. Disponível em: https://www.psicanaliseefilosofia.com.br/ad verbum/vol6_1/06_01_06felicidademalesta rciviliz.pdf.

10. Sebold RL. Reflexões Sobre a Felicidade e Sofrimento: Alguns Litorais. [Trabalho de Conclusão de Curso]. Porto Alegre (RS): Universidade Federal do Rio Grande do Sul - UFRGS; 2013. [citado em 20 de agosto de 2017]. Disponível em: https://www.lume.ufrgs.br/bitstream/handle /10183/95476/000913996.pdf?sequence=1

11. Fontenelle IA. O Trabalho da llusão: Produção, Consumo e Subjetividade na Sociedade Contemporânea. Rev Interações 2005; 10(19): 63-86. [citado em 20 de agosto de 2017]. Disponível em: http://www.redalyc.org/pdf/354/35401904.p df.

12. Camargo SG. Tristeza ou Depressão? Uma impropriedade significante. Rev Eletrônica SEPHORA 2008; 3(5): 1-7. [citado em 20 de agosto de 2017]. Disponível em: http://www.isepol.com/asephallus/numero_ 05/pdf/artigo_08.pdf.

13. Ferreira LVG. O Espetáculo do Simulacro na Cultura Contemporânea. [Trabalho de Conclusão de Curso]. Ariquemes (RO): Faculdade de Educação e Meio Ambiente - FAEMA; 2015.

14. Silva EBT. "Mecanismos de Defesa do Ego." [Trabalho de Curso]. Rev Psicologia.PT 2011; 3: 1-5. [citado em 20 de agosto de 2017]. Disponível em: http://www.psicologia.pt/artigos/textos/TL0 212.pdf.

15. Betsy K, Brasil MFAT. Saúde Mental e Corpo: Uma Aproximação à Psicossomática. Rev de Psicologia: Saúde Mental e Segurança Pública 1999; 2(1): 9 15. [citado em 20 de agosto de 2017]. Disponível em: http://revista.policiamilitar.mg.gov.br/period icos/index.php/psicologia/article/download/ 70/188.

16. Margarido FB. A Banalização do Uso de Ansiolíticos e Antidepressivos. Encontro: Rev de Psicologia 2012; 15(22): 131-146. [citado em 20 de agosto de 2017]. Disponível em: http://pgsskroton.com.br/seer/index.php/re nc/article/view/2485/2381.

17. Prata $\mathrm{HL}$ et al. Envelhecimento, Depressão e Quedas: Um Estudo com os Participantes do Projeto Prev-Quedas. Rev Fisioterapia em Movimento 2011; 24(3): 437-443. [citado em 20 de agosto de 2017]. Disponível em: https://periodicos.pucpr.br/index.php/fisio/a rticle/view/21083/20227.

18. Pereira IS. A Vontade de Sentido na Obra de Viktor Frankl. Rev Psicologia USP 
2007; 18(1): 125-136. [citado em 20 de agosto de 2017]. Disponível em: http://pepsic.bvsalud.org/pdf/psicousp/v18n 1/v18n1a07.pdf.

19. Matrix [Filme]. Direção/Produção: Lana Wachowski, Lilly Wachowski e Joel Silver. Austrália: Warnes Bros Pictures; 1999.
20. Foucault M, Ramalhete R. Vigiar e Punir: História da Violência nas Prisões. Petrópolis (RJ): Vozes; 1996.

21. Foucault M. História da Loucura na Idade Clássica. São Paulo (SP): Perspectiva; 1972.

\section{Como citar (Vancouver)}

Rocha VHC, Santos GP. Geração de pílulas azuis: a intensa busca pela felicidade na contemporaneidade. Rev Cient Fac Educ e Meio Ambiente [Internet]. 2018;9(1):465-483. DOI: http://dx.doi.org/10.31072/rcf.v9i1.562 